\title{
Comparison of the analgesic effect of ibuprofen with mesalamine after discectomy surgery in patients with lumbar disc herniation: A double-blind randomized controlled trial
}

Hamidreza Pazooki Toroudi, Mohammad Borghei Razavi ${ }^{1}$, Hamid Borghei Razavi², Reza Mostafavi Tabatabayi ${ }^{2}$, Yaser Tolouei Tabar², Seyyed Taha Yahyavi², Mehdi Montazer ${ }^{2}$

Department of Physiology, IRAN University of Medical Science, ${ }^{1}$ Department of Neurosurgery, Shabid Beheshti University of Medical Science, ${ }^{2}$ IRAN University of Medical Science, Iran

Address for correspondence: Dr. Mohammad Borghei Razavi, Number 217, Shahid Bahonar Street, Tehran, Iran.

E-mail:shbr61@yahoo.com

DOI: $10.4103 / 0028-3886.53292$

\begin{abstract}
Background: Pain management is an important component in the postoperative period following discectomy. Aims: We hypothesized that mesalamine considering its better safety profile, is likely to be a better choice, if it would be as effective as ibuprofen in controlling post-discectomy pain. Settings and Design: A doubleblind randomized controlled trial was performed on patients who underwent lumbar discectomy surgery. Materials and Methods: Of the 58 patients who had lumbar discectomy, 27 patients were randomized to oral ibuprofen $500 \mathrm{mg}$ and 31 patients to mesalamine $400 \mathrm{mg}$, three times a day for nine days following surgery. There was no placebo group. Severity of pain was assessed by using $10-\mathrm{cm}$ visual analogue scale (VAS), once before operation and for nine days after. Statistical Analysis: Mean \pm SD pain scores were compared between groups and the statistical difference was estimated by Student's test using SPSS (Version 13). We also calculated the power of each t-test. Repeated measure ANOVA was performed for measuring the effect of time. Results: The age range of the patients was 35 to 60 years (mean: 42.2 years). Mean \pm SD preoperative pain scores for ibuprofen or mesalamine-treated groups were $7.852 \pm 2.441$ and $7.806 \pm 2.892$, respectively. At the end of day 9 , mean \pm SD of pain score was $2.704 \pm 2.284$ and $2.717 \pm 2.273$ for ibuprofen and mesalamine-treated groups respectively. Both drugs significantly reduced postoperative pain and there was no statistically significant difference between the two groups. Conclusions: Since both drugs showed almost equal analgesic effect, considering its safety profile mesalamine, seems to be the preferred choice to alleviate post-discectomy surgery pain.
\end{abstract}

Key words: Discectomy, Ibuprofen, Mesalamine, pain, visual analogue scale

\section{Introduction}

Point prevalence of back pain, excluding sciatica, stenosis, or spinal column deformity is $33 \%^{[1]}$ and the annual prevalence is $73 \% .^{[2]}$ Annual incidence of debilitating back pain (visual analogue scale (VAS) score above 4) in an average healthy adult person ranges from 10 to $15 \% \cdot{ }^{[3]}$ Intervertebral disc herniation 
usually causes a throbbing pain extending to legs. In the majority of patients, symptoms of acute intervertebral disc herniation improve without surgical intervention. Nevertheless, surgical treatment is indicated in some patients in whom the symptoms prolong for longer period, when there is a deteriorating neurologic deficit or when the pain is not relieved by analgesics. Almost two-thirds of patients are completely relieved of pain after a lumbar discectomy surgery; the remaining patients experience a substantial improvement up to $85 \% .{ }^{[3]}$ Nevertheless, one of the postoperative problems is to control the inflammation and its consequent pain. The commonly used drug to relieve the pain is ibuprofen, a non-steroidal anti-inflammatory drug (NSAID). The cyclooxygenase (COX) pathway is the major target for NSAIDs, the most commonly used medications to treat pain, fever and inflammation. ${ }^{[4]} 5$-aminosalicylic acid (ASA), mesalamine is another anti-inflammatory drug which inhibits not only the COX pathway but also the lipoxygenase (LO) pathway, preventing generation of leukotrienes, ${ }^{\left[{ }^{[}\right]}$chemotactic responses to the leukotriene $\mathrm{B} 4,{ }^{[6]}$ and release of IL-1. ${ }^{[7]}$ This drug has good absorption, and provides post-prescription systemic effects by creating a sufficient blood level. ${ }^{[8,9]}$ In view of the above described features and also better safety profile, compared to ibuprofen, mesalamine seems to be an appropriate drug for relieving the inflammation and pain following discectomy surgery.

\section{Materials and Methods}

The double-blinded randomized controlled trial was carried out on individuals who underwent lumbar discectomy for intervertebral disc herniation (L4-L5 or L5-S1) in Day Hospital, Tehran, Iran, between January 2004 and January 2005. The surgery involved a midline incision, removing a part of the lamina over the disk (hemilamectomy or laminotomy), removing the lateral part of the flavom ligament, detecting the thecal sac and nerve root and excision of disk pieces.

All patients received methadone $5 \mathrm{mg}$ intramusclularly immediately after the surgery. Patients were randomly divided into two groups [Figure 1]. Of the 58 patients, 27 $(46.6 \%)$ were randomized to oral ibuprofen (Group 1), $500 \mathrm{mg}$ three times a day and $31(53.4 \%)$ to oral mesalamine (Group 2), $400 \mathrm{mg}$ three times a day for nine days. Both the drugs were supplied by Aria Pharmaceutical Company, Tehran, Iran. There was no placebo group as the hospital ethics board did not allow the same and also it is unethical not to give relief to the patient for severe pain. All subjects provided written informed consent to participate in the study. The local hospital Internal Review Board (IRB) had reviewed and approved the study protocol.

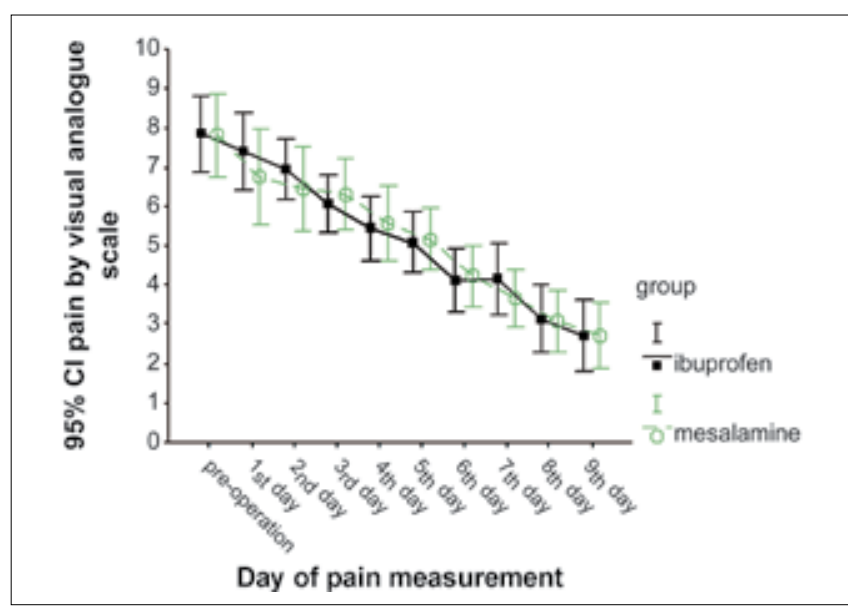

Figure 1: Comparison of pain scores in two groups (Group1 = lbuprofen $(n=27)$, Group2 $=$ Mesalamine $(n=31))$ from day 1 to day 9 after surgery. The error bars showed $95 \% \mathrm{Cl}$ of means (Mean $\pm 1.96 \mathrm{SE}$ )

Patients' pain was scored once prior to surgery and afterwards daily for nine days using Visual Analogue Scale (VAS). ${ }^{[10]}$ For consistency of conditions, pain measurement was carried out at 12:00 O'clock every day. The daily pain scores of the patients were recorded in data collection forms. Data of patients, who had taken another analgesic drug for whatever reason or had not consumed the prescribed drugs during the study period, were excluded [Figure 2].

We calculated the mean \pm SD of pain (VAS) scores and compared them with pooled $t$-test and also calculated the power of each $t$-test. We also used repeated measure ANOVA for measuring the effect of time. $P$ value $<0.05$ was considered statistically significant and minimal desired power considered was 0.8. The software used for the data analysis was SPSS v. 13.0.

\section{Results}

Patients' ages ranged between 35 and 60 years (mean: $42.2 \mathrm{yrs}$ ). Baseline characteristics were comparable between the two groups [Table $1 \mathrm{a} \& \mathrm{~b}$ ].

The pain score prior to surgery was 7.852 \pm 2.441 in Group 1 and $7.806 \pm 2.892$ in Group $2(P=0.949)$. The comparison of pain scores on day 1 through day 9 in the two groups is shown in Table 2. Because of the relatively low power of the tests we could not definitely show any difference. Therefore, we used repeated measure ANOVA to not only minimize the errors of multiple tests, but also to document the effect of time in decreasing the pain scores. Mauchly's test showed that the data were not spheroid $(P<0.001)$ suggesting the error covariance matrix of the orthonormalized-transformed dependent variables was not proportional to an identity matrix. Therefore, we reported Greenhouse Geisser results instead of spheroid assumed results. The results showed that the only 


\begin{tabular}{|c|c|c|c|c|c|}
\hline \multicolumn{6}{|c|}{ Table la: Baseline characteristics of the two groups } \\
\hline & Group 1 & \multicolumn{2}{|c|}{ Group 2} & \multicolumn{2}{|c|}{ Significance } \\
\hline $\begin{array}{l}\text { Age } \\
\text { Gender distribution } \\
\text { Preoperative pain }\end{array}$ & $\begin{array}{c}42.56 \pm 5.873^{*} \\
51.9 \% * *\end{array}$ & \multicolumn{2}{|c|}{$\begin{array}{c}51.6 \%^{* *} \\
7.806 \pm 2.892^{*}\end{array}$} & \multicolumn{2}{|c|}{$\begin{array}{l}0.986 \\
0.949\end{array}$} \\
\hline \multicolumn{6}{|c|}{${ }^{*}$ Mean $\pm \mathrm{SD},{ }^{* *}$ Percent of males } \\
\hline \multicolumn{6}{|c|}{ Table 1b: Baseline characteristics of the two groups } \\
\hline & \multicolumn{2}{|c|}{ Group $195 \% \mathrm{Cl}$} & \multicolumn{3}{|c|}{ Group $295 \% \mathrm{Cl}$} \\
\hline & Lower & Upper & Lov & & Upper \\
\hline Age & 40.23 & 44.88 & 39.8 & & 44.29 \\
\hline Gender & 32.86 & 70.94 & $33 . \varepsilon$ & & 69.37 \\
\hline Preoperative pain & 6.886 & 8.817 & 6.6 & & 8.821 \\
\hline
\end{tabular}

Table 2: Comparison of pain scores in the two groups (Group1 = Ibuprofen $(n=27)$, Group2 = Mesalamine $(n=31)$ ) from Day 1 to Day 9 after surgery

\begin{tabular}{|c|c|c|c|c|c|c|}
\hline Day & Group & Mean & SD & Mean diff & $P$ value & $\begin{array}{c}\text { Power } \\
\%\end{array}$ \\
\hline \multirow[t]{2}{*}{1} & Ibuprofen & 7.396 & 2.479 & 0.656 & 0.395 & 50.3 \\
\hline & Mesalamine & 6.742 & 3.329 & & & \\
\hline \multirow[t]{2}{*}{2} & Ibuprofen & 6.963 & 1.926 & 0.511 & 0.425 & 50.5 \\
\hline & Mesalamine & 6.452 & 2.879 & & & \\
\hline \multirow[t]{2}{*}{3} & Ibuprofen & 6.056 & 1.842 & -0.257 & 0.654 & 63 \\
\hline & Mesalamine & 6.313 & 2.423 & & & \\
\hline \multirow[t]{2}{*}{4} & Ibuprofen & 5.444 & 2.082 & -0.144 & 0.819 & 50 \\
\hline & Mesalamine & 5.589 & 2.608 & & & \\
\hline \multirow[t]{2}{*}{5} & Ibuprofen & 5.093 & 1.952 & -0.069 & 0.899 & 50 \\
\hline & Mesalamine & 5.161 & 2.137 & & & \\
\hline \multirow[t]{2}{*}{6} & Ibuprofen & 4.111 & 2.044 & -0.115 & 0.837 & 50 \\
\hline & Mesalamine & 4.226 & 2.16 & & & \\
\hline \multirow[t]{2}{*}{7} & Ibuprofen & 4.148 & 2.32 & 0.48 & 0.394 & 50.4 \\
\hline & Mesalamine & 3.668 & 1.938 & & & \\
\hline \multirow[t]{2}{*}{8} & Ibuprofen & 3.148 & 2.201 & 0.076 & 0.896 & 50.05 \\
\hline & Mesalamine & 3.073 & 2.173 & & & \\
\hline \multirow[t]{2}{*}{9} & Ibuprofen & 2.704 & 2.284 & -0.013 & 0.983 & 50 \\
\hline & Mesalamine & 2.717 & 2.273 & & & \\
\hline
\end{tabular}

\begin{tabular}{|c|c|c|c|c|c|}
\hline \multicolumn{6}{|c|}{ Table 2 (continued) } \\
\hline \multirow[t]{2}{*}{ Day } & \multirow[t]{2}{*}{ Group } & \multicolumn{2}{|c|}{$\begin{array}{c}95 \% \text { confidence } \\
\text { interval of the } \\
\text { mean }\end{array}$} & \multicolumn{2}{|c|}{$\begin{array}{l}95 \% \text { confidence } \\
\text { interval of the } \\
\text { mean diff }\end{array}$} \\
\hline & & Lower & Upper & Lower & Upper \\
\hline \multirow[t]{2}{*}{1} & Ibuprofen & 6.41 & 8.37 & -.907 & 2.220 \\
\hline & Mesalamine & 5.39 & 7.87 & & \\
\hline \multirow[t]{2}{*}{2} & Ibuprofen & 6.20 & 7.72 & -.798 & 1.820 \\
\hline & Mesalamine & 5.26 & 7.39 & & \\
\hline \multirow[t]{2}{*}{3} & Ibuprofen & 5.327 & 6.784 & -1.403 & .888 \\
\hline & Mesalamine & 5.323 & 7.124 & & \\
\hline \multirow[t]{2}{*}{4} & Ibuprofen & 4.621 & 6.268 & -1.398 & 1.110 \\
\hline & Mesalamine & 4.514 & 6.436 & & \\
\hline \multirow[t]{2}{*}{5} & Ibuprofen & 4.321 & 5.865 & -1.151 & 1.013 \\
\hline & Mesalamine & 4.281 & 5.852 & & \\
\hline \multirow[t]{2}{*}{6} & Ibuprofen & 3.302 & 4.920 & -1.226 & .996 \\
\hline & Mesalamine & 3.337 & 4.930 & & \\
\hline \multirow[t]{2}{*}{7} & Ibuprofen & 3.231 & 5.066 & -.640 & 1.600 \\
\hline & Mesalamine & 2.854 & 4.193 & & \\
\hline \multirow[t]{2}{*}{8} & Ibuprofen & 2.278 & 4.019 & -1.077 & 1.228 \\
\hline & Mesalamine & 2.176 & 3.774 & & \\
\hline \multirow[t]{2}{*}{9} & Ibuprofen & 1.800 & 3.607 & -1.224 & 1.198 \\
\hline & Mesalamine & 1.868 & 3.565 & & \\
\hline
\end{tabular}

effective factor in decreasing pain was time $(\mathrm{F}=59.683$, $\mathrm{df}=3.525, P=0.000$ ) and there was not any significant difference between the two groups of intervention $(\mathrm{F}=0.557, \mathrm{df}=3.525, P=0.672)$. However, the power of this equality was $17.4 \%$ so we can not say that the groups of intervention were really equal [Figure 2].

\section{Discussion}

This study could not prove the equivalence of these two drugs statistically, however on days 1, 2, 7 and 8 there was a trend in more pain relief with mesalamine compared to ibuprofen. The maximum difference was seen on day 3 , mean difference of -0.257 , which had the greatest power of $63 \%$, so we can assume that on day 3 pain scores were almost the same. Therefore, we can assume the next greatest difference, -0.144 for day 4 , as the greatest negative mean difference. Comparing this value with day 1,2 and 7 one can see that if they were not equivalent, the probability of having better effect with mesalamine is greater than this probability for Ibuprofen.

Mesalamine treatment has been proved effective in the management of ulcerative colitis. Patients with ulcerative colitis have frequently associated rheumatoid arthritis (RA). ${ }^{[11]}$ Mesalamine is reported to alleviate RA pain to some extent in patients with ulcerative colitis. ${ }^{[12-15]}$ Mesalamine is a salicylate derivative with analgesic property and inhibits both COX and LO pathways, also being a radical scavenger, ${ }^{[16,17]}$ It also inhibits connection between formly-metionyl-lucyl-phenylalanin and the receptors located on the neutrophils. ${ }^{[18]}$ Some studies suggest that mesalamine is more effective in ulcerative colitis because of its multiple actions on various functions of the immunity system. ${ }^{[18,19]}$ This drug enjoys a suitable systemic absorption, and it is anticipated that it provide post-prescription systemic effects by creating a sufficient blood level. ${ }^{[8,9]}$ Mesalamine is well tolerated and the side-effects are relatively few: Headache, dyspepsia, and dermal rash. Nephorotoxiciy is relatively rare and it appears it has no teratogenic side effect. ${ }^{[20]}$ Ibuprofen, a NSAIDs, inhibits the COX enzyme, thus exerts its anti-inflammatory and analgesic effects. This drug, however, has numerous side-effects because of COX I inhibition. The protection of the gastric mucosa by the prostaglandins being undermined, gastric ulceration is the most serious side-effect of the drug. The other less frequently reported side-effects of ibuprofen include: Thrombocytopenia, dermal rash, headache, vertigo, poor sight, amblyopia (very rarely), water and salt retention and edema. Ibuprofen is not recommended for pregnant and lactating women. ${ }^{[21]}$ 


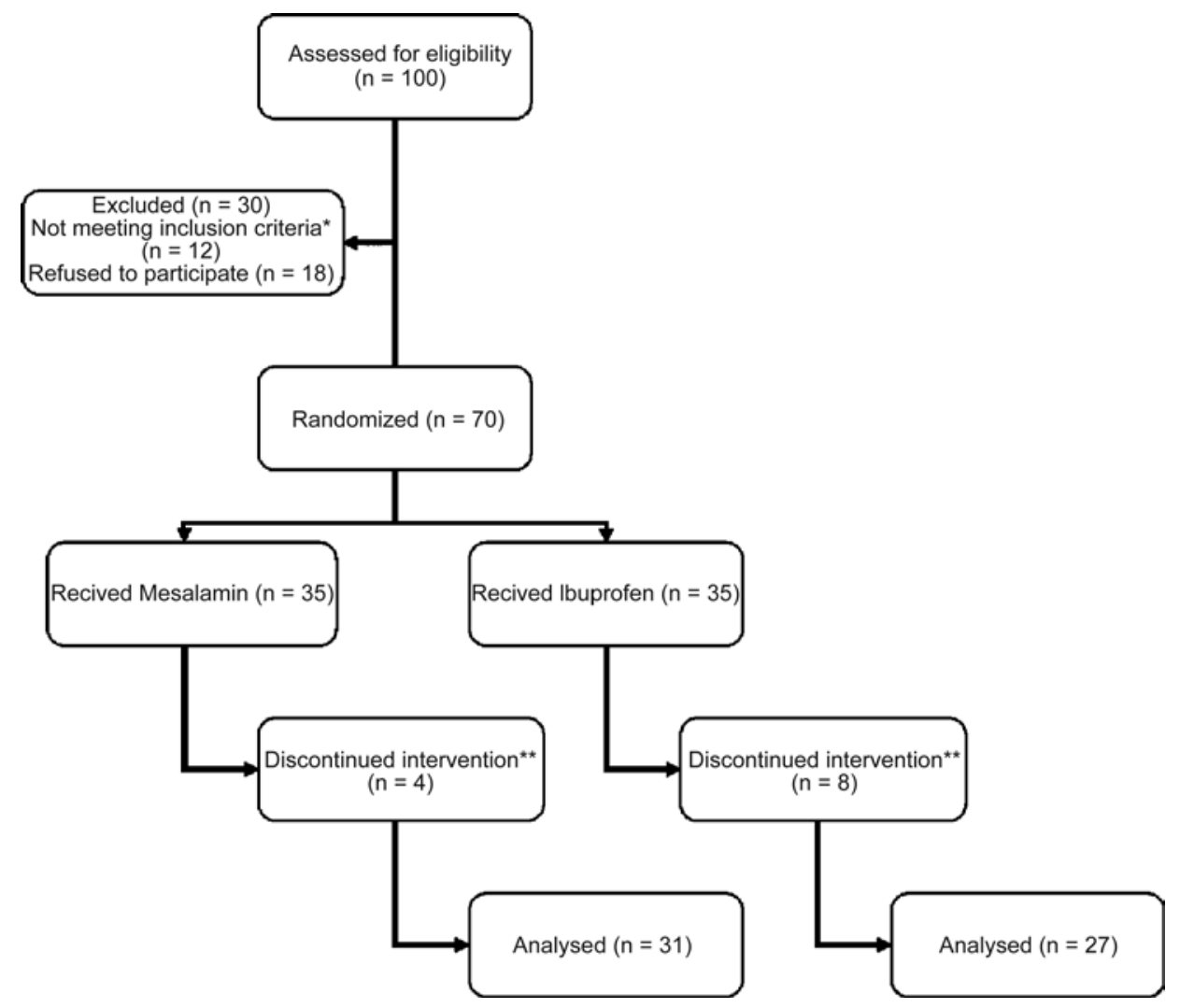

Figure 2: Flow diagram of subject progress through the phases of the trial

Since mesalamine has fewer side-effects compared to ibuprofen, it is safe to suggest that it might be a more suitable and better pain-controlling medication after a discectomy surgery. The present results suggest the equal effectiveness of mesalamine as a safe analgesic.

\section{Acknowledgment}

We extend our thanks and appreciation to Aria Pharmaceutical Company (Tehran, Iran) for the gift of Mesalamine and Ibuprofen.

\section{References}

1. Skovron ML, Szpalski M, Nordin M, Melot C, Cukier D. Sociocultural factors and back pain: A population-based study in Belgian adult. Spine 1994;19:129-37.

2. Cassidy JD. Carrol LJ, Cote P. The Saskatchewan Health and back pain survey: The prevalence of low back pain and related disability in Saskatchewan adults. Spine 1998;23:1860-6.

3. Carragee E, Cohen S. Reliability of LBP history in asymptomatic subjects? The prevalence and incidence of reported back pain correlates with surveillance frequency. In proceedings of $19^{\text {th }}$ annual meeting of the North American Spine Ssociety, Chicago: October 26-30, 2004;216.

4. Khanapure SP, Garvey DS, Janero DR, Letts LG. Eicosanoids in inflammation: Biosynthesis, pharmacology, and therapeutic frontiers. Curr Top Med Chem 2007;7:311-40.

5. Stenson WF, Lobos E. Sulfasalazine inhibits the synthesis of chemotactic lipids by neutrophils. J Clin Investig 1982;69:494-7.

6. Nielsen $\mathrm{OH}$, Verspaget HW, Elmgreen J. Inhibition of intestinal macrophage chemotaxis to leukotriene $\mathrm{B} 4$ by sulphasalazine, olsalazine, and 5-aminosalicylic acid. Aliment Pharmacol Ther 19881;2:203-11.

7. Rachmilewitz D, Karmeli F, Schwartz LW, Simon PL. Effect of Aminopbenols (5-ASA and 4-ASA) on colonic interleukin-l generation. Gut 1992;33:929-32.

8. Tokui K, Asai Y, Arakawa T, Matsumoto T, Nabeshima T. Comparative absorption of 5-aminosalicylic acid (5-ASA) after administration of a 5-ASA enema and salazosulf2pyridine (SASP) after an SASP suppository in Japanese volunteers. Biol Pharm Bull 2002;25:264-7.

9. Sandborn WJ, Hanauer SB, Buch A. Comparative pharmacokinetics of equimolar doses of 5-aminosalicylate administered as oral Mesalamine (Asacol) and balsalazide: A randomized, single-dose, crossover study in healthy volunteers. Aliment Pharmacol Ther 2004;19:1089-98.

10. Toliison CD, Satterthwaite JR, Tollison JW. Practical pain management. $3^{\text {rd }}$ ed. Lippincott Wil1iams and Wilkins; 2002.p.124.

11. Sugisaki K, Honma F, Iwadate H, Shio K, Shiova Y, Fukava E, et al. Ulcerative colitis occurring in the course of rheumatoid arthritis: A case successfully treated with Mesalamine enema. Intern Med 2004;43:1046-50.

12. Bird HA. Sulphasajazine, sulphapyridine or 5-aminosalicylic acid which is the active moiety in rheumatoid arthritis? $\mathrm{Br} \mathrm{J}$ Rheumatol 1995;34:16-9.

13. van der Horst-Bruinsma IE, Clegg DO, Dijkmans A. Treatment of ankylosing spondylitis with disease modifying antirheumatic drugs. Clin Exp Rheumatol 2002;20:S67-70.

14. Toussirot E, Wendling D. Current guidelines for the drug treatment of ankylosing spondylitis. Drugs 1998;56:225-40.

15. Dougados M, Dijkmans B, Khan M, Maksymowych W, van der Linden S, Brandt J. Conventional treatments for ankylosing spondylitis. Ann Rheum Dis 2002;61:iii40-50.

16. Ahnfelt-Ronne I, Nielsen OH. The anti-inflammatory moiety of Sulfasalazine, 5-minosalicylic acid, is a radical scavenger. Agents Actions $1987 ; 21: 191-4$

17. Aruoma OI, Wasil M, Halliwell B, Hoey BM, Butler J. The scavenging of oxidants by sulphasalazine and its metabolites: A possible 
contribution to their anti-in1lammatory effects? Biochem Pharmacol $1987 ; 36: 3739-42$.

18. Gaginella TS, Walsh RE. Sulfasalazine: Multiplicity of action. Dig Dis Sci 1992;37:801-12.

19. Greenfield SM, Punchard NA, Tear JP, Thomposon RP. The mode of action of the aminosalicylates in inflammatory bowel disease. Aliment Pharmacol Ther 1993;7:369-83.

20. Hardman JG, Limbird LE, Goodman Gilman A. Goodman and Gilman's The Pharmacological Basis of Therapeutics. Chapter 39. $10^{\text {th }}$ ed. 2001.p. 1050.
21. Hardman JG, Limbird LE, Goodman Gilman A. Goodman and Gilman's The Pharmacological Basis of Therapeuties. Chapter 27. 10 ${ }^{\text {th }}$ ed. 2001. p. 712 .

22. Charlesbrunicardi F, Andersen DK, Billiar TR, Dunn D, Hunter JG, Pollok RE. Schwartz's principles of surgery. Chapter $41.8^{\text {th }}$ ed. 2005. p. 1641.

Accepted on 06-01-2009

Source of Support: Nil, Conflict of Interest: None declared.

\section{Dispatch and return notification by E-mail}

The journal now sends email notification to its members on dispatch of a print issue. The notification is sent to those members who have provided their email address to the association/journal office. The email alerts you about an outdated address and return of issue due to incomplete/incorrect address.

If you wish to receive such email notification, please send your email along with the membership number and full mailing address to the editorial office by email. 